\title{
Temporal changes in the most effective pollinator of a bromeliad pollinated by bees and hummingbirds
}

\author{
Roberta Luisa Barbosa Leal ${ }^{1}$, Marina M Moreira ${ }^{1,2}$, Alessandra R Pinto ${ }^{3}$, Julia O Ferreira ${ }^{1}$, Miguel Rodriguez- \\ Girones $^{4}$, Leandro Freitas ${ }^{\text {Corresp. } 1}$ \\ 1 Jardim Botânico do Rio de Janeiro, Rio de Janeiro, Rio de Janeiro, Brazil \\ 2 Centro de Ciências Agrárias, Universidade Federal do Espírito Santo, Alegre, Espírito Santo, Brazil \\ 3 Programa de Pós-Graduação em Ecologia, Universidade Federal do Rio de Janeiro, Rio de Janeiro, Rio de Janeiro, Brazil \\ 4 Estación Experimental de Zonas Áridas, Almería, Spain \\ Corresponding Author: Leandro Freitas \\ Email address: Ifreitas.jbot@gmail.com
}

A generalist pollination system may be characterized through the interaction of a plant species with two or more functional groups of pollinators. The spatiotemporal variation of the most effective pollinator is the factor most frequently advocated to explain the emergence and maintenance of generalist pollination systems. There are few studies merging variation in floral visitor assemblages and the efficacy of pollination by different functional groups. Thus, there are gaps in our knowledge about the variation in time of pollinator efficacy and frequency of generalist species. In this study, we evaluated the pollination efficacy of the floral visitors of Edmundoa lindenii (Bromeliaceae) and their frequency of visits across four reproductive events. We analysed the frequency of the three groups of floral visitors (large bees, small bees, and hummingbirds) through focal observations in the reproductive events of 2015, 2016, 2017, and 2018. We evaluated the pollination efficacy (fecundity after one visit) through selective exposure treatments and the breeding system by manual pollinations. We tested if the reproductive success after natural pollination varied between the reproductive events, and also calculated the pollen limitation index. Edmundoa lindenii is a self-incompatible and parthenocarpic species, requiring the action of pollinators for sexual reproduction. Hummingbirds had higher efficacy than large bees, and small bees acted only as pollen larcenists. The relative frequency of the groups of floral visitors varied between the reproductive events. Pollen limitation has occurred only in the reproductive event of 2017, when visits by hummingbirds were scarce and reproductive success after natural pollination was the lowest. We conclude that hummingbirds and large bees were the main and the secondary pollinators of $E$. lindenii, respectively, and that temporal variations in the pollinator assemblages had effects on its reproductive success. Despite their lower pollination efficacy, large bees ensured seed set when hummingbirds failed. Thus, we provide Peer) reviewing PDF | (2019:02:35011:2:0:NEW 19 Feb 2020) 
evidence that variable pollination environments may favour generalization, even under differential effectiveness of pollinator groups if secondary pollinators provide reproductive assurance. 
1 Temporal changes in the most effective pollinator of a bromeliad pollinated by bees and 2 hummingbirds

3

4 Roberta Luísa Barbosa Leal ${ }^{1}$, Marina Muniz Moreira ${ }^{1,2}$, Alessandra Ribeiro Pinto ${ }^{3}$, Julia de

5 Oliveira Ferreira ${ }^{1}$, Miguel Angel Rodríguez-Gironés ${ }^{4}$, Leandro Freitas ${ }^{1}$

6

71 Jardim Botânico do Rio de Janeiro, Rio de Janeiro, RJ, Brazil

82 Universidade Federal do Espírito Santo, Centro de Ciências Agrárias, Alegre, ES, Brazil

93 Universidade Federal do Rio de Janeiro, Programa de Pós-Graduação em Ecologia, Rio de 10 Janeiro, RJ, Brazil

114 Estación Experimental de Zonas Áridas, Almería, Spain

Corresponding Author:

Leandro Freitas

Rua Pacheco Leão, 915, Jardim Botânico, Rio de Janeiro, Brasil.

Email address: 1freitas.jbot@gmail.com

\section{ABSTRACT}

\section{Background}

A generalist pollination system may be characterized through the interaction of a plant species with two or more functional groups of pollinators. The spatiotemporal variation of the most effective pollinator is the factor most frequently advocated to explain the emergence and maintenance of generalist pollination systems. There are few studies merging variation in floral visitor assemblages and the efficacy of pollination by different functional groups. Thus, there are gaps in our knowledge about the variation in time of pollinator efficacy and frequency of generalist species. In this study, we evaluated the pollination efficacy of the floral visitors of Edmundoa lindenii (Bromeliaceae) and their frequency of visits across four reproductive events. Methods

We analysed the frequency of the three groups of floral visitors (large bees, small bees, and hummingbirds) through focal observations in the reproductive events of 2015, 2016, 2017, and 
32 2018. We evaluated the pollination efficacy (fecundity after one visit) through selective exposure treatments and the breeding system by manual pollinations. We tested if the reproductive success after natural pollination varied between the reproductive events, and also calculated the pollen limitation index.

\section{Results}

Edmundoa lindenii is a self-incompatible and parthenocarpic species, requiring the action of pollinators for sexual reproduction. Hummingbirds had higher efficacy than large bees, and small bees acted only as pollen larcenists. The relative frequency of the groups of floral visitors varied between the reproductive events. Pollen limitation has occurred only in the reproductive event of 2017, when visits by hummingbirds were scarce and reproductive success after natural pollination was the lowest.

\section{INTRODUCTION}

In most plants, flowers are visited by a diverse assemblage of animals, which characterizes generalist pollination systems (Waser et al., 1996). Based on the behavior and morphophysiological traits, floral visitors can be arranged in different functional groups of pollinators, which may differ in their contribution to the plant reproductive success (Fenster et al., 2004). This difference in contribution occurs as these pollinators can vary in frequency of visits and ability to transfer pollen (Shuttleworth \& Johnson, 2008; Ollerton, 2017). Studies encompassing generalist pollination systems mainly report floral visitor assemblages and visitation rates (e.g., Thompson, 2001; Freitas \& Sazima, 2006; Scrok \& Varassin, 2011); despite not all visitors are actual pollinators (Armbruster, Fenster \& Dudash, 2000; Ollerton, 2017). Therefore, studies that evaluate the pollination efficacy (for instance, measuring seed set after one visit, Freitas, 2013) of different functional groups of pollinators are necessary to better understand pollinators' relevance on plants with a generalist pollination system.

Based on the principle of "the most effective pollinator," a plant having more than one functional group of pollinators could be interpreted as an intermediary stage in the shift from one specialized pollinator to another (Stebbins, 1970). An alternative explanation is that generalist systems are not transient and may be favored in certain scenarios, for example, under unpredictable pollination environments (Herrera, 1988; 1996; Waser et al., 1996; Armbruster et al., 2000; Gómez \& Zamora, 2006; Ollerton et al., 2007). Accordingly, the spatiotemporal 
63

64

65

66

67

68

69

variation of the most effective pollinator is the factor most frequently advocated to explain the emergence and maintenance of generalist pollination systems. Several studies have explored temporal variation in composition and frequency of floral visitors (Fenster \& Dudash, 2001; Ivey, Martinez \& Wyatt, 2003; Zych et al., 2018). Other studies have quantified the effectiveness (i.e., the product of efficacy times visitation rate, after Herrera, 1987; Freitas 2013) of different pollinator species or functional groups (e.g., Amorim, Galetto \& Sazima, 2013; Salas-Arcos, Lara \& Ornelas, 2017). However, information about floral visitor assemblages and their effectiveness on pollination over multiple reproductive events is restricted to a few systems (Herrera, 1987; 1988; Larsson, 2005; Wiggam \& Ferguson, 2005). Thus, there are gaps in knowledge about the variation of pollinators in generalist plants and their effectiveness over time.

Generalized pollination systems have ecological and evolutionary dimensions (Armbruster et al., 2000), therefore the effect of several pollinators in the process of evolutionary generalization depends on the selective pressures exerted by those floral visitors. In this sense, differences in pollination efficacy (sensu Freitas, 2013) among functional groups may be enhanced if the variations in the pollination environment affect the plant reproductive success. For instance, pollen limitation (PL), the lower fruit and/or seed production due to inadequate pollen receipt, is widespread in angiosperms (Ashman et al., 2004; Knight et al., 2005), and similarly to the pollinator effectiveness, its magnitude varies at several scales (Bennett et al., 2018). However, how temporal variations in the pollination environment and PL levels are related is a fundamental but poorly understood aspect to a better understanding of the mechanisms that lead to the maintenance of generalized pollination systems (see Koski et al., 2018). 2017) and hummingbirds are the main group of pollinators of them (Benzing, 2000). However, several species are known to have mixed pollination systems, for example involving hummingbirds and bees or bats (Givnish et al., 2014). Edmundoa lindenii (Regel) Leme bears flowers that are visited by both hummingbirds and bees in montane tropical forests, however we do not know the role of those groups on the plant sexual reproduction over time. Here, we evaluated the efficacy of three groups of floral visitors and their frequency of visits over four reproductive events. In particular, we addressed the following questions: (1) Do hummingbirds, 
94 large bees and small stingless bees pollinate this species, considering the high divergence of 95 traits between them? (2) Is the pollination efficacy of hummingbirds higher than large bees, since

96 97 98 99

100

101

102

103

104

105

106

107

108

109

110

111

112

113

114

115

116

117

118

119

120

121

122

123

hummingbirds pollinate most species of Bromeliaceae? (3) Are the relative and gross frequencies of floral visits by each group equivalent over four reproductive events, since clear environmental variations were not noted in those years? (4) However, if they are not equivalent, are those variations in frequency related to the reproductive success in natural conditions and the occurrence of pollen limitation?

\section{MATERIALS AND METHODS}

\section{Study site and species}

This study was conducted in an area covered by montane Atlantic Forest, located in the Serra dos

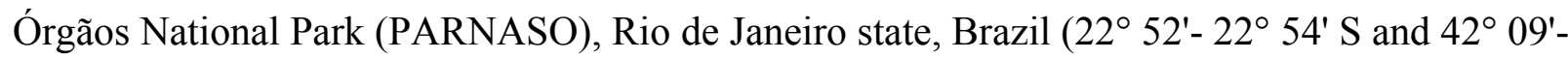
$45^{\circ} 06^{\prime} \mathrm{W}$, ca. $960 \mathrm{~m}$ a.s.1.) among four reproductive events (from 2014 to 2018). The average annual rainfall at the study site is $2,436 \mathrm{~mm}$, with the rainiest period between December and March and colder and drier months from June to August. The mean annual temperature is 18.6 ${ }^{\circ} \mathrm{C}$, with minimum and maximum monthly temperatures of $13.7^{\circ} \mathrm{C}$ and $22.9^{\circ} \mathrm{C}$ (climate data for 2015 to 2018 from the meteorological station located inside the PARNASO). The field research reported here was performed using the required permit (SISBIO No. 34882, No. 432793).

Edmundoa lindenii (Regel) Leme (Bromeliaceae - Bromelioideae) is a terrestrial, saxicolous, or epiphyte herb, endemic to the Atlantic Forest in south and southeastern Brazil (Martinelli et al., 2008; BFG, 2015). In the study area, this species blooms between December and February and produces fruits between March and April; its flowers are visited by bees and hummingbirds (R.L.B. Leal et al., pers. obs.).

\section{Floral biology}

We measured inflorescences of E. lindenii ( $\mathrm{n}=16$ individuals) directly in the field with a digital calliper, considering the following traits: scape length, inflorescence diameter, and bract length. Flowers $(n=73)$ from 28 individuals were collected in the field, stored in $70 \%$ alcohol, and measured in the laboratory with a digital calliper considering the following structures: corolla tube length (i.e., from septal nectary to the opening of the corolla) and the width of the corolla tube opening. We counted the number of ovules in 25 flowers $(\mathrm{n}=15$ individuals). 
To analyse the colour quantitatively, we measured the spectral reflectance of petals,

125

126

127

128

129

130

131

132

133

134

135

136

137

138

139

140

141

142

143

144

145

146

147

148

149

150

151

152

153

154 sepals, and bracts. For this, 12 flowers ( $n=6$ individuals) were collected in the field, stored in thermal bags containing moist paper, and brought to the laboratory, where they were immediately measured (Lunau et al., 2011). We measured the reflectance using an USB2000 spectrophotometer (OceanOptics, Inc., Dunedin, FL, USA) coupled with a deuterium-halogen light source (DH-2000; OceanOptics, Inc., Ostfildern, Germany), with a light emission range between 215 and $1700 \mathrm{~nm}$. We took all reflectance measurements at a $45^{\circ}$ angle in relation to the plant structure, and we used barium sulphate as the white standard and black paper as the black standard (Chittka \& Kevan, 2005).

We used the logarithm version of the receptor noise-limited model (Vorobyev et al., 2001) to compare the colours of the petals, sepals, and bracts. Chromatic distances were calculated according to the trichromatic formulation for bees and the tetrachromatic formulation for hummingbirds (Vorobyev \& Osorio, 1998). We modelled spectral sensitivity curves using data from Sephanoides sephaniodes (Herrera et al., 2008) to estimate hummingbird colour distances, and from Bombus terrestris for bees (Telles \& Rodriguéz-Gironés, 2015). In all cases, we used standard daylight illumination (D65 - Wyszecki \& Stiles, 1982). Using these models, we determined the spectral location of each structure in a colour space for each pollinator.

The distance between two points in a colour space provides an approximation of the perceived colour difference (Endler \& Mielke, 2005). We evaluated colour distances between sepals, petals, and bracts. Using the receptor noise-limited model, we estimated that two colours were discriminable if their distance was greater than 0.27 units for bees (Telles \& RodriguezGironés, 2015) and 1.0 for hummingbirds (Vorobyev et al., 1998). For representation, we also calculated the colour loci of the flower colours in the respective colour space models: the colour hexagon for bees (Chittka 1992) and the colour tetrahedron for hummingbirds (Vorobyev et al., 1998).

\section{Nectar}

We measured the nectar volume in flowers previously bagged in bud stage, with a graduated microliter syringe (Hamilton, Nevada, USA), and the concentration with hand-held refractometer (Bellingham + Stanley Eclipse, UK). To evaluate nectar production during anthesis, without the effect of nectar removal, 36 flowers ( $n=10$ individuals) previously bagged at the bud stage were 
155 measured once after anthesis onset. In total, we performed measurements at four different times

156 of the day: 7:00 am $(n=10$ flowers $) ; 8: 30$ am $(n=10) ; 10: 00$ am $(n=10)$; and 11:30 am $(n=6)$.

157 To evaluate if nectar removal stimulates its secretion, 24 flowers were submitted to four

158 treatments $(n=6$ individuals, four flowers per individual - one flower per treatment per

159 individual): $\mathrm{R}=$ nectar was measured once at 11:00 am; $\mathrm{R} 1=$ nectar was measured twice (at

$16010: 00$ am and 11:30 am); R2 = nectar was measured three times (at 8:30 am, 10:00 am and 11:30

$161 \mathrm{am}$ ); and R3 nectar was measured four times (at 7:00 am, 8:30 am, 10:00 am and 11:30 am).

162 Thus, for the treatments R1, R2, and R3, nectar was remeasured on the same flowers. We

163 calculated the total amount of sugar $(\mathrm{mg})$ per flower by multiplying nectar volume $(\mu \mathrm{L})$ by its

164 corrected concentration $(\mathrm{mg} / \mu \mathrm{L})$ according to Dafni, Kevan \& Husband (2005).

\section{Breeding system and pollen limitation}

166 We evaluated the breeding system and pollen limitation (PL) through manual pollination

167 treatments. Floral buds of different individuals were previously bagged with "voile" bags, and

168 the flowers submitted to the following treatments: (1) spontaneous self-pollination - 20 flowers

169 from 8 individuals, were bagged and not manipulated in 2016; (2) hand self-pollination - 49

170 flowers from 20 individuals, were supplemented manually with pollen from the same flower and

171 bagged in 2016; (3) hand cross-pollination - 130 flowers from 47 individuals, were supplemented

172 with pollen from other individual, located at least $10 \mathrm{~m}$ away, and then bagged. We conducted

173 the cross-pollination treatment in the years 2016 (26 flowers), 2017 (48 flowers), and 2018 (56

174 flowers). (4) Pollination under natural conditions - 131 flowers from 36 individuals were marked

175 and kept unbagged. We evaluated the flowers from natural pollination in 2016 (49 flowers), 2017

176 (20 flowers), and 2018 (62 flowers). At the end of the experiments we collected the fruits and

177 counted the number of seeds per fruit in the laboratory. We calculated the index of pollen

178 limitation as IPL $=1-P_{n} / P_{c}$ where $P_{n}$ is the proportion of seed-bearing fruits multiplied by the

179 mean number of seeds per fruit of flowers exposed to natural pollination, and $P_{c}$ is the

180 proportion of seed-bearing fruits multiplied by the mean number of seeds per fruit of flowers

181 after hand cross-pollination (adapted from Lloyd and Schoen, 1992; Larson and Barrett, 2000).

182 We used as response variable of reproductive success in all analyses such an estimate combining

183 fruits bearing seeds and the number of seeds, which is appropriate because E. lindenii is

184 parthenocarpic (i.e., flowers develop into fruits independent of pollination). Values of IPL $\leq 0.2$

185 indicate absence of PL, whereas IPL > 0.8 indicates strong PL (Freitas, Wolowski \& Sigiliano, 
186 2010). We assessed the self-incompatibility by the index of incompatibility (ISI), a relative

187 measure of the seeds produced after self- and cross-pollination (Zapata and Arroyo, 1978).

188 Species with ISI $<0.30$ may be classified as self-incompatible (Ramirez \& Brito, 1990).

189

190 Frequency and efficacy of floral visitors

191 We performed focal observations (sensu Dafni et al., 2005) to evaluate the identity of floral

192 visitors and their frequency of visits, by censuses of 30-min per individual ( $\mathrm{n}=190$ individuals)

193 between 6:00 am and 12:00 am, totalizing 184 hours of observation. Observations were done in 194 four reproductive events, in the years 2015 (43.5 hours, $\mathrm{n}=50$ individuals), 2016 (39.0 hours, $\mathrm{n}$ $195=42), 2017$ (51.0 hours, $n=48)$, and 2018 (50.5 hours, $n=50)$. Images and videos were captured 196 during the visits to evaluate the foraging behaviour and the floral resources obtained. The visits 197 were identified as legitimate or illegitimate by the expected mode of pollination, considering the 198 shape and arrangement of the flower parts (sensu Irwin et al., 2010; Freitas, 2018). Specimens 199 of insects were collected for posterior identification. We grouped the floral visitors into three 200 functional groups based on identity, body size and foraging behaviour, as following:

201 hummingbirds, large bees (length $\geq 10 \mathrm{~mm}$ ), and small bees $(<10 \mathrm{~mm})$.

202

203

204

205

206

207

208

209

210

211

212

213

214

215

We evaluated the efficacy of the three functional groups of floral visitors through experiments of selective exposition. In this experiment, flowers previously bagged at the bud stage were exposed to a single visit by any visitor of the three functional groups, as follows: small bees (48 flowers in 2016), large bees (20 flowers in 2017 and 60 in 2018), and hummingbirds (20 flowers in 2017 and 65 in 2018). Here we also considered the proportion of seed-bearing fruits multiplied by the mean number of seeds per fruit as the response variable of the pollination efficacy by each functional group.

\section{Data analyses}

We performed all the analyses in $\mathrm{R}$ version 3.4.4 (R Development Core Team, 2018). We evaluated the production of nectar during anthesis and the effect of nectar removal in nectar secretion by analyses of variance (one-way ANOVA), using the function aov. We assessed the differences between treatments (time of anthesis and number of removals) by Tukey HSD posthoc test, using the function TukeyHSD.

Peer] reviewing PDF | (2019:02:35011:2:0:NEW 19 Feb 2020) 
We conducted a linear model to evaluate if the reproductive success after natural

217

218

219

220

221

222

223

224

225

226

227

228

229

230

231

232

233

234

235

236

237

238

239

240

241

242

243

244

245

246

pollination varied between three reproductive events (2016, 2017, and 2018). Prior to analyses, we cubic-root transformed values of the response variable to meet the normality assumptions. We used the reproductive events (three levels: 2016, 2017, and 2018) as fixed effect. We established the model using the function $I m$ and we tested the model assumptions by visual inspection of the residuals using the qqnorm function. We calculated the significance of each term in the model using the function Anova (Type II) from the car package (Kuznetsova et al., 2017) and the differences between levels of categorical factors using the function lsmeans from lsmeans package (Lenth, 2016).

To evaluate whether hummingbirds and large bees differ in their efficacy, we conducted a linear model. Prior to analyses, we cubic-root transformed values of the response variable to meet the normality assumptions. We used the functional group of pollinators (two levels: hummingbirds and large bees) and the year when the treatments were conducted (two levels: 2017 and 2018) as fixed effects. We established the model using the function $l m$ and we tested the model assumptions by visual inspection of the residuals using the qqnorm function. We calculated the significance of each term in the model using the function Anova (Type II) from the car package (Kuznetsova et al., 2017) and the differences between levels of categorical factors using the lsmeans package (Lenth, 2016). We did not compare the efficacy of small bees as no seeds were produced after their visits.

To evaluate if the frequency of visits varies between the four reproductive events and the group of floral visitors, we conducted a log-linear model for categorical data (Wood, 2017). We used the relative frequency of visits as a response variable, and the reproductive events (four levels: 2015, 2016, 2017, and 2018) and the functional groups (three levels: hummingbirds, large bees, and small bees) as fixed effects. We established the model using the glm function with the family set to poisson (Lindsey, 1997). We tested the model assumptions by visual inspection of the residuals. We calculated the significance of each term in the model using the anova function (test $=$ Chisq $)$ and the differences between levels of categorical factors using the emmeans function available in the emmeans package.

\section{RESULTS}

Floral biology 
247 The flowers of $E$. lindenii are grouped in a compound corymboid inflorescence with $c a$. 100-150

248 flowers, inserted in the leaf rosette (Fig. 1). Inflorescence diameter reached $121.32 \pm 17.01 \mathrm{~mm}$

249 and scape length $296.87 \pm 23.86 \mathrm{~mm}$ (mean \pm SD throughout the text). The flowers are

250 hermaphrodite, with the androecium presenting six stamens included in the corolla and anthers

251 with longitudinal dehiscence (Fig. 1). The gynoecium is also included in the corolla and the style

252 ends in a three-lobed stigma (Fig. 1). The inferior and trilocular ovary contained $197.9 \pm 54.12$

253 ovules. The length of bracts and sepals was $55.15 \pm 6.99 \mathrm{~mm}$ and $26.0 \pm 4.0 \mathrm{~mm}$, respectively.

254 The corolla is tubular (length: $17.95 \pm 2.92 \mathrm{~mm})$ with a narrow opening $(3.11 \pm 1.17 \mathrm{~mm})$. The

255 flowers have diurnal anthesis, characterized by the presence of exposed pollen grains and

256 receptive stigma. The anthesis began at around 06:00 am and lasted for about six hours when

257 corolla closed. The secretion of nectar started in the beginning of anthesis, and it did not increase

258 over time $(\mathrm{F}=0.44 ; \mathrm{df}=3 ; \mathrm{p}=0.726$; Fig. $2 A)$. However, the removal of nectar stimulated new

259 secretion $(\mathrm{F}=6.632, \mathrm{df}=3, \mathrm{p}=0.00273$, Fig. $2 B)$.

260 The bracts reflect red wavelengths, whereas the corolla is UV-reflecting white, and the

261 sepals are UV-absorbing white (Fig. 3). The colour of petals, sepals, and bracts, as well as open

262 or closed flowers, is distinguishable by bees and hummingbirds. Flower colour was 1-7 times

263 above the discrimination criteria (0.27) for bee vision (petals-sepals $4 \pm 1$, bracts-sepals $4 \pm 2$ )

264 and 5-15 times above the discrimination criteria (1.0) for hummingbirds (petals-sepals $8 \pm 2$,

265 bracts-sepals $12 \pm 4$, bracts-petals $15 \pm 7$ ).

266

\section{Breeding system and pollen limitation}

268 Edmundoa lindenii is self-incompatible (ISI = 0.08; Table 1) and parthenocarpic (Table 1),

269 requiring the action of pollinators for sexual reproduction. We observed that the reproductive

270 success after natural pollination varied between reproductive events (ANOVA: $F=12.9, \mathrm{df}=2 \mathrm{p}$

$271<0.001$ ). The lowest reproductive success occurred in the reproductive event of 2017 (contrasts:

272 2016-2017: $\mathrm{t}=5.050 ; \mathrm{df}=103 ; \mathrm{p}<0.001 ; \mathbf{2 0 1 6 - 2 0 1 8}: \mathrm{t}=2.100 ; \mathrm{df}=103 ; \mathrm{p}=0.095 ;$ 2017-2018:

$273 \mathrm{t}=-3.840 ; \mathrm{df}=103 ; \mathrm{p}<0.001 ;$ Fig. 4). Pollen limitation was expressive only in 2017 (PL index:

$2742016=-0.21,2017=0.70,2018=-0.003)$.

275

276 Floral visitors and temporal variation 
277 The flowers of $E$. lindenii were visited by 11 species of animals belonging to three functional

278 groups (hummingbirds, large bees, and small bees; Table 2). Hummingbirds were the group with

279 the highest species richness with seven species (Table 2; Fig. 1). The small bee T. spinipes was

280 the only visitor that conducted illegitimate visits, resulting in damage of corolla and/or anthers

281 by chewing. Hummingbirds and large bees foraged for nectar acting as legitimate visitors, and 282 small bees collected pollen.

283 The pollinator functional group affected the reproductive success of E. lindenii (Table 3)

284 and hummingbirds had higher efficacy than large bees (contrast: $\mathrm{t}=3.015 \mathrm{df}=148, \mathrm{p}=0.003$;

285 Table 4; Fig. 5). Small bees did not act as pollinators, as none of the flowers they visited

286 produced seeds. The frequency of visits varied between functional groups of floral visitors with

287 significant interaction between functional group and reproductive event (Table 4; Fig. 6).

288

289 DISCUSSION

290 The frequency of floral visitors' groups (hummingbirds, large bees, and small bees) varied

291 between reproductive events of $E$. lindenii, and this variation resulted in a reduction in the

292 natural pollination in one year, when pollen limitation was also recorded. The existence of year-

293 to-year changes in the composition of floral visitors has been found in several systems (Schemske

294 \& Horvitz, 1984; Traveset \& Sáez, 1997; Price et al., 2005; Olesen et al., 2008; Petanidou et al.,

295 2008), while in others, pollination efficacy between different years was studied (Fishbein \&

296 Venable, 1996; Stoepler et al., 2012). However, there are fewer studies that consider both plant

297 reproductive success and variations in the pollinator assemblages along time (Herrera, 1990;

298 Fleming et al., 2001; Salas-Arcos et al., 2017). Thus, through observational and experimental

299 approaches, we have shown that the reproductive success of a generalist species responded to

300 temporal variation of its assemblage of pollinators.

$301 \quad$ Overall hummingbirds had higher efficacy and visitation frequency than large bees, so

302 they could be pointed as the main pollinators of E. lindenii. Hummingbirds also act as the main

303 pollinators in other species of Bromeliaceae (Schmid et al., 2011; Magalhães et al., 2018).

304 However, large bees did not always act as secondary pollinators of E. lindenii: they were the

305 main pollinators when the frequency of visits by hummingbirds was low. Pollinators belonging

306 to different functional groups may vary in their pollination effectiveness, exerting pressures

307 toward specialization (Stebbins, 1970; Rosas-Guerrero et al. 2014). Thus, evolution of a 
308

309

310

311

312

313

314

315

316

317

318

319

320

321

322

323

324

325

326

327

328

329

330

331

332

333

334

335

336

337

338

generalized pollination system is expected when different pollinators play the same role as selective agents or if the less effective pollinators provide reproductive assurance, offsetting fluctuations of the most effective pollinators. This could be the case for large bees and $E$. lindenii, as they can ensure sexual reproduction when hummingbirds fail. In short, our results are consistent with the hypothesis that the maintenance of generalist pollination is related to the existence of variable pollination environments (Waser et al., 1996) and support that combined measurements of reproductive success and pollinator assemblages along time and space as an interesting approach in this regard (see Gómez \& Zamora, 2006 for additional suggestions). Curiously, there was no evidence of declining populations of hummingbirds in the study area in 2017, the causes of the drastic reduction of visits to the flowers of E. lindenii by hummingbirds that year are completely unknown.

Despite the differences on effectiveness, flowers of $E$. lindenii are attractive to both hummingbirds and bees. Floral visitors identify and select flowers using a variety of characteristics, including size and color contrasts (Papiorek et al., 2016), and hummingbirds and bees can detect different color spectra (Chittka \& Waser, 1997; Vorobyev \& Osorio, 1998). The floral traits of E. lindenii are detectable by both groups of floral visitors. Petals had UV reflection, sepals absorbed UV, and bracts were red. These results correspond to the expected pattern for attraction of bees and hummingbirds, as bees have a spectrum of vision that includes UV wavelengths, around 300-400 nm (Kevan, Chittka \& Dyer, 2001), and hummingbirds are known for their preference for red-coloured flowers that mostly are UV-absorbent (Lunau et al. 2011). However, trade-offs between selective pressures exerted by different pollinators may occur if they differ in preference for floral traits (Gervasi \& Schiestl, 2017). As pointed out above, we may speculate that the temporal fluctuation in the visitor frequencies of $E$. lindenii may reduce the probability of pollinators exerting consistent selective pressures on its floral traits (Schemske \& Horvitz, 1984; Gómez \& Zamora, 2006). In this case, attractive and non-restrictive flowers for large bees are important for reproductive assurance in reproductive events with a low frequency of hummingbirds, thus it would not be expected a shift to specialized hummingbirdflowers. However, further experiments are needed to support that selection toward pollination specialization by hummingbirds is restrained in this system.

In addition to visual signals, the nectar of $E$. lindenii is accessible to hummingbirds and large bees, thus its flowers are attractive and legitimately accessible to the two groups. The 
339 dynamics of nectar production influences the behaviour of pollinators during visits to the flowers

340 (Parachnowitsch, Manson \& Sletvold, 2018). Although nectar production of E. lindenii did not

341 increase over time, its removal stimulated further secretion. Similar results have been found in

342 other bromeliads, including some species visited by hummingbirds and bees (Galetto \&

343 Bernardello, 1992; Ordano \& Ornelas, 2004). Nectar secretion after withdrawal may favor

344 repeated visits to the flower. This is consistent with our results of the pollination efficacy

345 experiment in E. lindenii. Specifically, seed set after one visit by a large bee or hummingbird

346 was lower than seed set of flowers exposed to pollinators during the whole anthesis, indicating

347 that more than one visit is necessary to achieve maximum fecundity in this species. At last,

348 nectar secretion after removals and repeated visits by pollinators could be related to the male

349 component of the reproductive success (see Ordano \& Ornelas, 2004).

350 The population of E. lindenii at PARNASO was self-incompatible, but self-compatibility

351 has been registered in other populations of this species (Matallana et al., 2010). Variations

352 between self- incompatibility and self-compatibility within species are common in plant

353 evolution and may indicate transitions between reproductive systems (Igic, Lande \& Kohn,

354 2008). Studies have shown that compatibility barriers can be broken by genetic changes (such as

355 mutations) (e.g., Sassa et al., 1997), physiological factors, elevated temperatures, and stress (e.g.,

356 Tezuka et al., 1997), allowing for self-pollination. Moreover, breeding systems may be related to

357 the degree of pollination generalization, linking shifts in pollination and incompatibility systems.

358 For instance, Wessinger and Kelly (2018) found a relationship between self-compatibility and

359 attributes related to the attraction of hummingbirds, including red flowers and loss of floral

360 aroma and UV- absorbing pigments. In contrast, we found self-incompatibility and UV-

361 absorbing sepals in E. lindenii despite higher frequency of visits by hummingbirds. Self-

362 incompatibility in this species seems to work as a barrier to autogamous pollination, since small

363 bees access the anthers, make long visits to the flower, and manipulate the pollen. In fact,

364 pollinators usually do not operate independently of herbivores (florivores in this case), which

365 may generate a trade-off between the fitness functions by each kind of organism (Ashman, 2002;

366 Gómez \& Zamorra, 2006; Gélvez-Zúñiga et al., 2018).

367

368 CONCLUSION 
369 Our results allow us to conclude that hummingbirds and large bees were the main and the

370 secondary pollinators of E. lindenii, respectively. Moreover, small bees had a negative effect on

371 its reproduction. These results could indicate a higher degree of specialization of this system than

372 the apparent generalization considering floral visitor composition (see Padyšáková et al., 2013),

373 which would be in accordance with the most effective pollinator principle (Stebbins, 1970).

374 However, temporal variations in the pollinator assemblages had effects on reproductive success

375 of E. lindenii, leading to the occurrence of pollen limitation when visits by hummingbirds were

376 scarce. Despite their lower pollination efficacy, large bees ensured seed set when hummingbirds

377 failed. Plant pollination generalization has been associated with similar effectiveness by the

378 different pollinators (Waser et al., 1996). However, we provide evidence that variable pollination

379 environments may favour generalization, even under differential effectiveness of pollinator

380 groups if secondary pollinators provide reproductive assurance. This reinforces the idea of

381 different mechanisms driving the evolution of generalized pollination systems (Schiestl, Balmer

$382 \&$ Gervasi, 2018).

383

384 ACKNOWLEDGMENTS

385 The authors thank Gabriel C. Rocha for field and data analysing assistance; Cristovão

386 Albuquerque (Publicase, Brazil) for language editing; Mariano Ordano for critical review; and

387 the staff of the Serra dos Órgãos National Park for logistics support and for allowing access to

388 Park facilities.

389

390

391

392

393

394

395

396

397

\section{REFERENCES}

Amorim FW, Galetto L, Sazima M. 2013. Beyond the pollination syndrome: nectar ecology and the role of diurnal and nocturnal pollinators in the reproductive success of Inga sessilis (Fabaceae). Plant biology 5(2): 317-327 DOI: 10.1111/j.1438-8677.2012.00643.x

Armbruster S, Fenster C, Dudash M. 2000. Pollination 'principles' revisited: specialization, pollination syndromes, and the evolution of flowers. In: Totland $\varnothing$, ed. The Scandinavian Association for Pollination Ecology honours Knut Fagri. Oslo: Det Norske VidenskapsAkademi, 179-200. 
398

399

400

401

402

403

404

405

406

407

408

409

410

411

412

413

414

415

416

417

418

419

420

421

422

423

424

425

426

427

428

Ashman T. 2002. The role of herbivores in the evolution of separate sexes from

$$
\text { hermaphroditism. Ecology 83: } 11751184 \text { DOI: 10.1890/0012- }
$$

9658(2002)083[1175:trohit]2.0.co;2

Ashman T, Knight TM, Steets JA, Amarasekare P, Burd M, Campbell DR, Dudash MR, Johnston MO, Mazer SJ, Mitchell RJ, Morgan MT, Wilson WG. 2004. Pollen limitation of plant reproduction: ecological and evolutionary causes and consequences. Ecology, 85: 2408-2421 DOI:10.1890/03-8024

Bates D, Maechler M, Bolker B, Walker S. 2015. lme4: Linear mixed-effects models using Eigen and S4. R package version 1.1-7. 2014.

BFG. 2015. Growing knowledge: an overview of seed plant diversity in Brazil. Rodriguésia 66: 1085-1113 DOI: 10.1590/2175-7860201566411

Bennett JM, Steets JA, Burns JH, Durka W, Vamosi JC, Arceo-Gomez G, Burd M, Burkle LA, Ellis AG, Freitas L, Li J, Rodger JG, Wolowski M, Xia J, Ashman TL, Knight TM. 2018. GloPL, a global data base on pollen limitation of plant reproduction. Scientific Data 5: 180249 DOI: $10.1038 /$ sdata.2018.249

Chittka, L. 1992. The colour hexagon: a chromaticity diagram based on photoreceptor excitations as a generalized representation of colour opponency. Journal of Comparative Physiology A 170(5): 533-543 DOI: 10.1007/bf00199331

Chittka L, Waser NM. 1997. Why red flowers are not invisible to bees. Israel Journal of Plant Sciences 45(2-3), 169-183 DOI: 10.1080/07929978.1997.10676682

Chittka L, Kevan PG. 2005. Flower colour as advertisement. In Dafni A, Kevan PG, Husband BC, eds. Practical Pollination Biology. Cambridge, Canada: Enviroquest, 157-196.

Dafni, A., Kevan, P. G., \& Husband, B. C. 2005. Practical pollination biology. Practical pollination biology. Haifa: Institute of Evolution, University of Haifa

Fenster CB, Armbruster WS, Wilson P, Dudash MR, Thomson JD. 2004. Pollination syndromes and floral specialization. Annual Review of Ecology, Evolution, and Systematics 35: 375-403 DOI: 10.1146/annurev.ecolsys.34.011802.132347

Fenster CB, Dudash MR. 2001. Spatiotemporal variation in the role of hummingbirds as pollinators of Silene virginica. Ecology 82(3): 844-851 DOI: 10.2307/2680202

Fishbein M, Venable DL. 1996. Diversity and temporal change in the effective pollinators of Asclepias tuberosa. Ecology 77(4): 1061-1073 DOI: 10.2307/2265576 
429 Fleming TH, Sahley, CT, Holland JN, Nason JD, Hamrick JL. 2001. Sonoran desert columnar 430 cacti and the evolution of generalized pollination systems. Ecological Monographs 71(4)

431

432

433

434

435 436

437

438

439

440

441

442

443

444

445

446

447

448

449

450

451

452

453

454

455

456

457

458

459 511-530 DOI: 10.1890/0012-9615(2001)071[0511:sdccat]2.0.co;2

Freitas L. 2013. Concepts of pollinator performance: is a simple approach necessary to achieve a standardized terminology? Brazilian Journal of Botany 36: 3-8 DOI: 10.1007/s40415-0130005-6

Freitas L. 2018. Precisamos falar sobre o uso impróprio de recursos florais. Rodriguésia 68(4): 2223-2228 DOI: 10.1590/2175-7860201869446

Freitas L, Sazima M. 2006. Pollination biology in a tropical high-altitude grassland in Brazil: interactions at the community level. Annals of the Missouri Botanical Garden 93: 465-516 DOI: 10.3417/0026-6493(2007)93[465:PBIATH]2.0.CO;2

Freitas L, Wolowski M, Sigiliano MI. 2010. Ocorrência de limitação polínica em plantas de Mata Atlântica. Oecologia Australis 14(1): 251-265 DOI: 10.4257/oeco.2010.1401.15

Galetto, L., \& Bernardello, L. M. 1992. Extrafloral nectaries that attract ants in Bromeliaceae: structure and nectar composition. Canadian Journal of Botany 70(6): 1101-1106 DOI: $10.1139 / \mathrm{b} 92-136$

Gélvez-Zúñiga I, Teixido AL, Neves AC, Fernandes GW. 2018. Floral antagonists counteract pollinator-mediated selection on attractiveness traits in the hummingbird-pollinated Collaea cipoensis (Fabaceae). Biotropica 50: 797-804 DOI:10.1111/btp.12574

Gervasi DD, Schiestl FP. 2017. Real-time divergent evolution in plants driven by pollinators. Nature Communications 8(1), 14691 DOI: 10.1038/ncomms14691

Givnish TJ. 2017. A New World of plants. Science 358 (6370): 1535-1536 DOI: 10.1126/science.aar4191

Givnish TJ, Barfuss MH, Van Ee B, Riina R, Schulte K, Horres R, Gonsiska PA, Jabaily RS, Crayn DM, Smith JA, Winter K, Brown GK, Evans TM, Holst BK, Luther H, Till W, Zizka G, Berry PE, Sytsma KJ. 2014. Adaptive radiation, correlated and contingent evolution, and net species diversification in Bromeliaceae. Molecular Phylogenetics and Evolution 71: 5578 DOI: 10.1016/j.ympev.2013.10.010

Gómez JM, Zamora R. 2006. Ecological factors that promote the evolution of generalization in pollination systems. In Waser N, Ollerton J. eds. Plant-pollinator interactions: from specialization to generalization. Chicago: University of Chicago Press, 145-165. 
460 Herrera CM. 1987. Components of pollinator "quality": comparative analysis of a diverse insect

461

462

463

464

465

466

467

468

469

470

471

472

473

474

475

476

477

478

479

480

481

482

483

484

485

486

487

488

489

490 assemblage. Oikos 50: 79-90 DOI: 10.2307/3565403

Herrera CM. 1988. Variation in mutualisms - the spatio-temporal mosaic of a pollinator assemblage. Biological Journal of the Linnean Society 35: 95-125 DOI: 10.1111/j.10958312.1988.tb00461.x

Herrera CM. 1990. Daily patterns of pollinator activity, differential pollinating effectiveness, and floral resource availability, in a summer-flowering Mediterranean shrub. Oikos 58(3): 277-288 DOI: $10.2307 / 3545218$

Herrera CM. 1996. Floral traits and plant adaptation to insect pollinators: a devil's advocate approach. In Lloyd DG., Barrett SCH. eds. Floral biology: studies on floral evolution in animal-pollinated plants. New York: Chapman \& Hall, 65-87.

Herrera G, Zagal JC, Diaz M, Fernández MJ, Vielma A, Cure M, Martinez J, Bozinovic F, Palacios AG. 2008. Spectral sensitivities of photoreceptors and their role in colour discrimination in the green-backed firecrown hummingbird (Sephanoides sephaniodes). Journal of Comparative Physiology A 194(9): 785-794 DOI: 10.1007/s00359-008-0349-8.

Igic B, Lande R, Kohn JR. 2008. Loss of self-incompatibility and its evolutionary consequences. International Journal of Plant Sciences 169(1): 93-104 DOI: 10.1086/523362

Ivey CT, Martinez P, Wyatt R. 2003. Variation in pollinator effectiveness in swamp milkweed, Asclepias incarnata (Apocynaceae). American Journal of Botany 90(2): 214-225 DOI: 10.3732/ajb.90.2.214

Irwin RE, Bronstein JL, Manson JS, Richardson L. 2010. Nectar robbing: ecological and evolutionary perspectives. Annual Review of Ecology, Evolution, and Systematics 41(1): 271-292 DOI: 10.1146/annurev.ecolsys.110308.120330

Kevan PG, Chittka L, Dyer AG. 2001. Limits to the salience of ultraviolet: lessons from colour vision in bees and birds. Journal of Experimental Biology 204(14): 2571-2580. Available at https://jeb.biologists.org/content/jexbio/204/14/2571.full.pdf(accessed 28 Sept 2019)

Kuznetsova A, Brockhoff PB, Christensen RHB. 2017. lmerTest Package: tests in linear mixed effects models. Journal of Statistical Software 82(13): 1-26 DOI: 10.18637/jss.v082.i13

Larson BM, Barrett SC. 2000. A comparative analysis of pollen limitation in flowering plants. Biological Journal of the Linnean Society 69(4): 503-520 DOI: .1111/j.10958312.2000.tb01221.x 
491 Larsson M. 2005. Higher pollinator effectiveness by specialist than generalist flower-visitors of 492 unspecialized Knautia arvensis (Dipsacaceae). Oecologia 146: 394-403 DOI:

493 10.1007/s00442-005-0217-y

494

Lenth RV. 2016. Least-squares means: the R package 1smeans. Journal of Statistical Software 495 69(1): 1-33 DOI: 10.18637/jss.v069.i01

496

Lindsey JK. 1997. Applying generalized linear models. New York: Springer.

497

Lloyd DG, Schoen DJ. 1992. Self- and cross-fertilization in plants. I. Functional dimensions.

498 International Journal of Plant Sciences 153: 358-369. Available at

499 http://www.jstor.org/stable/2995676 (accessed 20 Oct 2019).

500 Lunau K, Papiorek S, Eltz T, Sazima M. 2011. Avoidance of achromatic colours by bees 501 provides a private niche for hummingbirds. Journal of Experimental Biology 214(9): $1607-$ 502 503 504 505

506

507 508

509 1612 DOI: $10.1242 /$ jeb.052688

Magalhães AFP, Maruyama PK, Tavares LAF, Martins RL. 2018. The relative importance of hummingbirds as pollinators in two bromeliads with contrasting floral specializations and breeding systems. Botanical Journal of the Linnean Society 188(3): 316-326 DOI: 10.1093/botlinnean/boy050

Martinelli G, Vieira CM, Gonzalez M, Leitman P, Piratininga A, Costa AF, Forzza RC 2008. Bromeliaceae da Mata Atlântica brasileira: lista de espécies, distribuição e conservação. Rodriguésia 59(1): 209-258 DOI: doi.org/10.1590/2175-7860200859114

Matallana G, Godinho MAS, Guilherme FAG, Belisario M, Coser TS, Wendt T. 2010. Breeding systems of Bromeliaceae species: evolution of selfing in the context of sympatric occurrence. Plant Systematics and Evolution 289(1-2): 57-65 DOI: 10.1007/s00606-0100332-z

Olesen JM, Bascompte J, Elberling H, Jordano P. 2008. Temporal dynamics in a pollination network. Ecology 89(6): 1573-1582 DOI: 10.1890/07-0451.1

Ollerton J. 2017. Pollinator diversity: distribution, ecological function, and conservation. Annual Review of Ecology, Evolution, and Systematics 48: 353-376 DOI: 10.1146/annurev-ecolsys110316-022919

Ordano M, Ornelas JF. 2004. Generous-like flowers: nectar production in two epiphytic bromeliads and a meta-analysis of removal effects. Oecologia 140(3): 495-505 DOI:

10.1007/s00442-004-1597-0 
522 Padyšáková E, Bartoš M, Tropek R, Janeček S. 2013. Generalization versus specialization in

523 pollination systems: visitors, thieves, and pollinators of Hypoestes aristate (Acanthaceae).

$524 \quad$ PLoS One 8(4):e59299 DOI:10.1371/journal.pone.0059299

525 Papiorek S, Junker RR, Alves-dos-Santos I, Melo GA, Amaral-Neto LP, Sazima M, Wolowski

526 M, Freitas L, Lunau K. 2016. Bees, birds and yellow flowers: pollinator-dependent

527 convergent evolution of UV patterns. Plant Biology 18(1): 46-55 DOI: 10.1111/plb.12322

528 Parachnowitsch AL., Manson JS, Sletvold N. 2018. Evolutionary ecology of nectar. Annals of

529 Botany 123(2): 247-261 DOI: 10.1093/aob/mcy132

530 Petanidou T, Kallimanis AS, Tzanopoulos J., Sgardelis SP, Pantis JD. 2008. Long-term

531 observation of a pollination network: fluctuation in species and interactions, relative

532 invariance of network structure and implications for estimates of specialization. Ecology

533 Letters 11(6): 564-575 DOI: 10.1111/j.1461-0248.2008.01170.x

534 Price MV, Waser NM, Irwin RE, Campbell DR, Brody AK. 2005. Temporal and spatial

535 variation in pollination of a montane herb: a seven-year study. Ecology 86(8): 2106-2116

536 DOI: $10.1890 / 04-1274$

537 Ramirez N, Brito Y. 1990. Reproductive biology of a tropical palm swamp community in the

538 Venezuelan llanos. American Journal of Botany 77(10): 1260-1271 DOI: 10.1002/j.1537-

$539 \quad 2197.1990 . t b 11378 . x$

540 Rosas-Guerrero V, Aguilar R, Martén-Rodríguez S, Ashworth L, Lopezaraiza-Mikel M, Bastida

541 JM, Quesada M. 2014. A quantitative review of pollination syndromes: do floral traits

542 predict effective pollinators? Ecology Letters 17: 388-400. DOI: 10.1111/ele.12224

543 Salas-Arcos L, Lara C, Ornelas JF. 2017. Reproductive biology and nectar secretion dynamics of

544 Penstemon gentianoides (Plantaginaceae): a perennial herb with a mixed pollination system?

545 PeerJ 5: e3636 DOI: 10.7717/peerj.3636

546 Sassa H, Hirano H, Nishio T, Koba T. 1997. Style-specific self-compatible mutation caused by

547 deletion of the S-RNase gene in Japanese pear (Pyrus serotina). The Plant Journal 12(1):

548 223-227 DOI: 10.1046/j.1365-313X.1997.12010223.x

549 Schemske DW, Horvitz CC. 1984. Variation among floral visitors in pollination ability: a

550 precondition for mutualism specialization. Science 225(4661): 519-521 DOI:

$551 \quad 10.1126 /$ science.225.4661.519 
552 Schiestl FP, Balmer A, Gervasi DD. 2018. Real-time evolution supports a unique trajectory for

553 generalized pollination. Evolution 72: 2653-2668. DOI:10.1111/evo.13611

554 Schmid S, Schmid VS, Zillikens A, Harter-Marques B, Steiner J. 2011. Bimodal pollination

555 system of the bromeliad Aechmea nudicaulis involving hummingbirds and bees. Plant

556 Biology 13: 41-50 DOI: 10.1111/j.1438-8677.2010.00348.x

557 Scrok GJ, Varassin IG. 2011. Reproductive biology and pollination of Aechmea distichantha

558 Lem. (Bromeliaceae). Acta Botanica Brasilica 25(3): 571-576 DOI: 10.1590/s0102-

$559 \quad 33062011000300009$

560 Shuttleworth A, Johnson SD. 2008. Bimodal pollination by wasps and beetles in the African

561 milkweed Xysmalobium undulatum. Biotropica 40: 568-574 DOI: 10.1111/j.1744-

$562 \quad 7429.2008 .00418 . x$

563 Stebbins GL. 1970. Adaptive radiation of reproductive characteristics in angiosperms, I:

564 Pollination mechanisms. Annual Review of Ecology and Systematics 1: 307-326 DOI:

565 10.1146/annurev.es.01.110170.001515

566 Stoepler TM, Edge A, Steel A, O'Quinn RL, Fishbein M. 2012. Differential pollinator

567 effectiveness and importance in a milkweed (Asclepias, Apocynaceae) hybrid zone.

568 American Journal of Botany 99(3): 448-458 DOI: 10.3732/ajb.1100272

569 R Core Team 2018. R: A language and environment for statistical computing. R Foundation for

$570 \quad$ Statistical Computing, Vienna, Austria. Available at https://www.R-project.org/.

571 Telles FJ, Rodríguez-Gironés MA. 2015. Insect vision models under scrutiny: what bumblebees

572 (Bombus terrestris terrestris L.) can still tell us. The Science of Nature 102(1-2): 4 DOI:

$573 \quad 10.1007 / \mathrm{s} 00114-014-1256-1$

574 Tezuka T, Tsuruhara A, Suzuki H, Takahashi SY. 1997. A connection between the self-

575 incompatibility mechanism and the stress response in lily. Plant and Cell Physiology 38:

576 107-112. DOI: 10.1093/oxfordjournals.pcp.a029139

577 Thompson JD. 2001. How do visitation patterns vary among pollinators in relation to floral

578 display and floral design in a generalist pollination system? Oecologia 126(3): 386-394

579 DOI: $10.1007 / \mathrm{s} 004420000531$

580 Traveset A, Sáez E. 1997. Pollination of Euphorbia dendroides by lizards and insects: spatio-

581 temporal variation in patterns of flower visitation. Oecologia 111(2): 241-248 DOI:

$582 \quad 10.1007 /$ PL00008816 
583 Vorobyev M, Osorio D. 1998. Receptor noise as a determinant of colour thresholds. Proceedings 584 of the Royal Society of London. Series B: Biological Sciences 265(1394): 351-358 DOI:

$585 \quad 10.1098 / \mathrm{rspb} .1998 .0302$

586 Vorobyev MD, Osorio D, Bennett ATD, Marshall NJ, Cuthill IC. 1998. Tetrachromacy, oil 587 droplets and bird plumage colours. Journal of Comparative Physiology A. 183: 621-633

$588 \quad$ DOI: $10.1007 / \mathrm{s} 003590050286$

589 Vorobyev MD, Brandt R, Peitsch D, Laughlin SB, Menzel R. 2001. Colour thresholds and 590 receptor noise: behaviour and physiology compared. Vision Research 41:639-53. DOI: $591 \quad 10.1016 / \mathrm{S} 0042-6989(00) 00288-1$

592 Waser NM, Chittka L, Price MV, Williams NM, Ollerton J. 1996. Generalization in pollination $593 \quad$ systems, and why it matters. Ecology 77: 1043-1060 DOI: 10.2307/2265575.

594 Wessinger CA, Kelly JK. 2018. Selfing can facilitate transitions between pollination syndromes. 595 American Naturalist 191(5): 582-594. DOI: 10.1086/696856

596 Wiggam S, Ferguson CJ. 2005. Pollinator importance and temporal variation in a population of 597 Phlox divaricata L. (Polemoniaceae). American Midland Naturalist 154(1): 42-54 DOI: 10.1674/0003-0031(2005)154[0042:PIATVI]2.0.CO;2

599 Wood SN. 2017. Generalized addictive models: an introduction with R. Boca Raton: Chapman 600 and Hall.

601 Zapata TR, Arroyo MTK. 1978. Plant reproductive ecology of a secondary deciduous tropical 602 forest in Venezuela. Biotropica 10(3): 221-230 DOI: 10.2307/2387907

603 Zych M, Junker RR, Nepi M, Stpiczyńska M, Stolarska B, Roguz K. 2018. Spatiotemporal 604 variation in the pollination systems of a supergeneralist plant: is Angelica sylvestris 605 (Apiaceae) locally adapted to its most effective pollinators? Annals of Botany 123(2): 415$606 \quad 428$ DOI: $10.1093 / \mathrm{aob} / \mathrm{mcy} 140$ 


\section{Figure 1}

fig1 - Edmundoa lindenii flowers were visited by three functional groups: hummingbirds, large bees, and small bees.

(A) Inflorescence and flowers; (B) Visit by the hummingbird Amazilia fimbriata; (C) visit by the large bees Bombus morio; (D) visit by the small bee Trigona spinipes. All observations were made in the montane Atlantic Forest at Serra do Órgãos National Park, southeastern Brazil. 


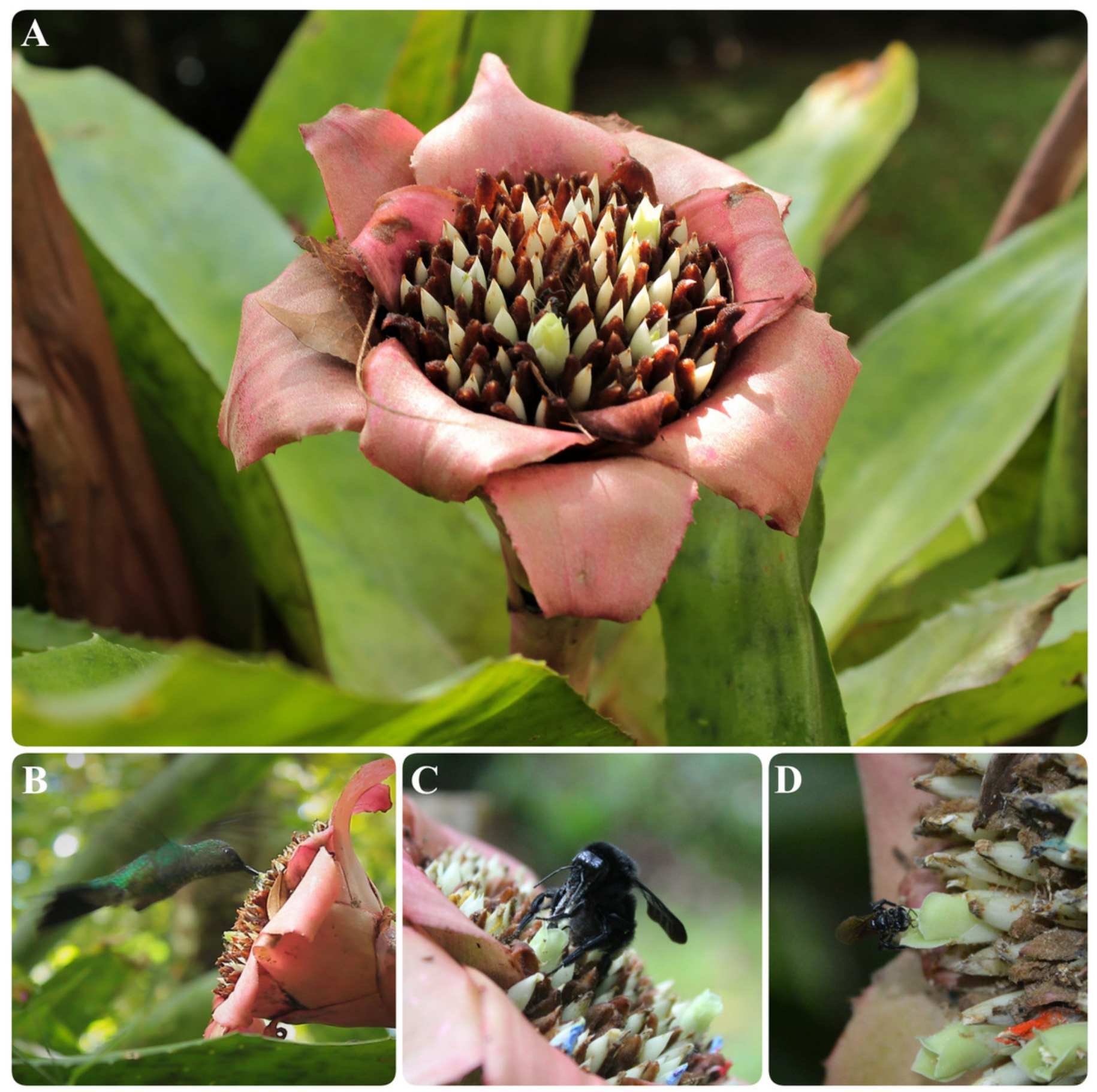




\section{Figure 2}

Nectar production in Edmundoa lindenii flowers did not increase during the anthesis, but the nectar removal stimulated new secretion.

(A) Nectar production along the anthesis at four different times of the day: 7:00h; 8:30h;

10:00h; and 11:30h. (B) Nectar production after experimental removal of nectar: $\mathrm{R}=\mathrm{no}$ removal, sampled one time at 11:00h; R1 = one removal, sampled two times at 10:00h and 11:30h; R2 = two removals, sampled three times at 8:30h, 10:00h and 11:30h; and R3 = three removals, sampled four times at 7:00h, 8:30h, 10:00h and 11:30h. The horizontal line in the both boxplots represents the median values, the upper and lower sides of the box represent the corresponding quartiles, and vertical lines are minimum and maximum values of the data range. Dots are outliers. Different letters indicate statistical significance between pairs of years $(p<0.05)$ by ANOVA post-hoc test (TukeyHSD). 

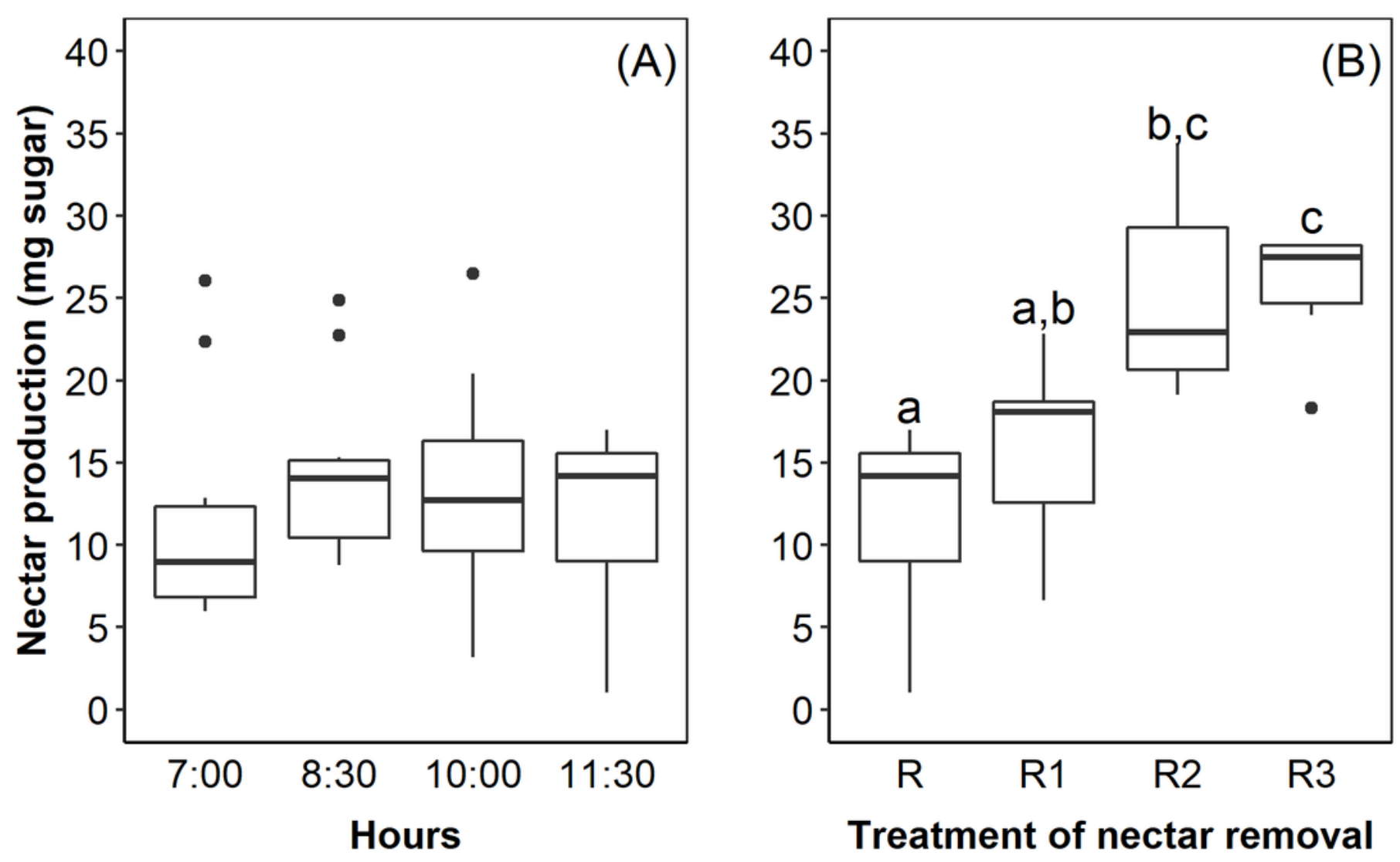


\section{Figure 3}

fig3 - Attractive structures of Edmundoa lindenii include red bracts, UV- reflecting white petals, and UV-absorbing white sepals, and can be detected by bees and hummingbirds.

(A) The reflectance spectra of attractive structures in E. lindenii inflorescences. For each structure, the colored line represents the mean reflectance and the corresponding color shading represents the standard deviation. Red = bract reflectance; blue = sepal reflectance; green $=$ petal reflectance. $(B)$ Hexagon model for bee vision based on the photoreceptors of Bombus terrestris. (C) Tetrahedron model for bird vision based in the photoreceptors of Sephanoides sephaniodes. In both models, the gray point represents achromatic center, the red point represents mean loci for bracts, the blue point indicates the mean loci for sepals, and the green point represents mean loci for petals.
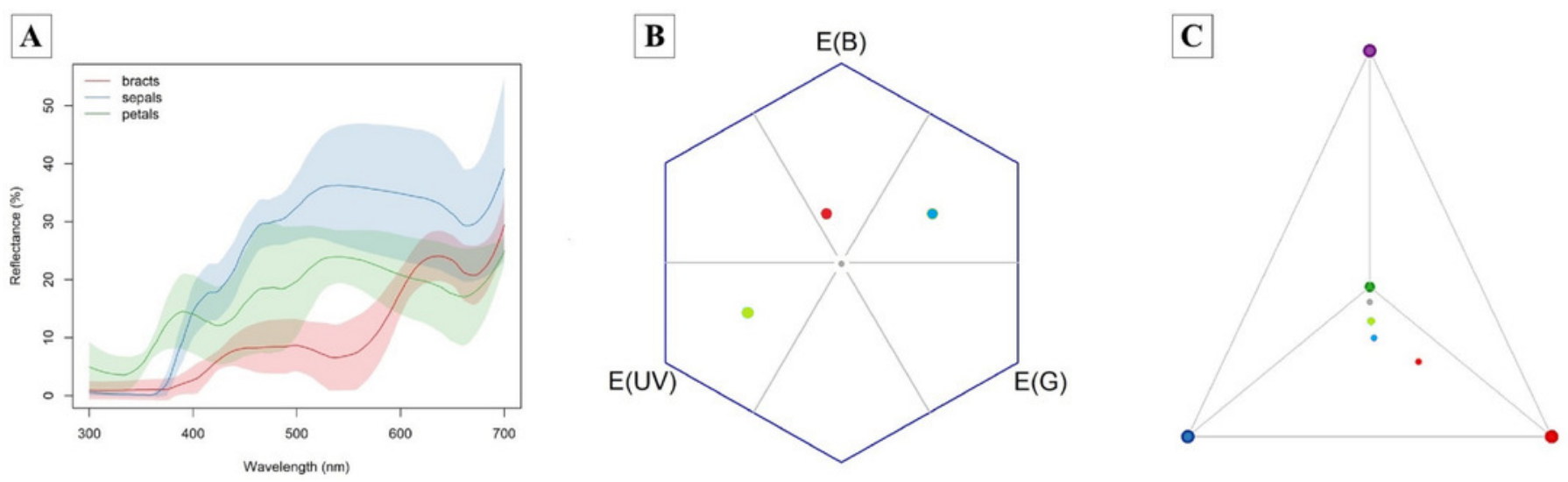


\section{Figure 4}

fig4 - The reproductive event of 2017 presented the lower reproductive success by natural pollination.

Reproductive success after natural pollination among three reproductive events (2016, 2017, and 2018). Seeds = proportion of fruits with seeds formed multiplied by the number of seeds in each fruit. Different letters show statistically significant difference $(p<0.05)$.

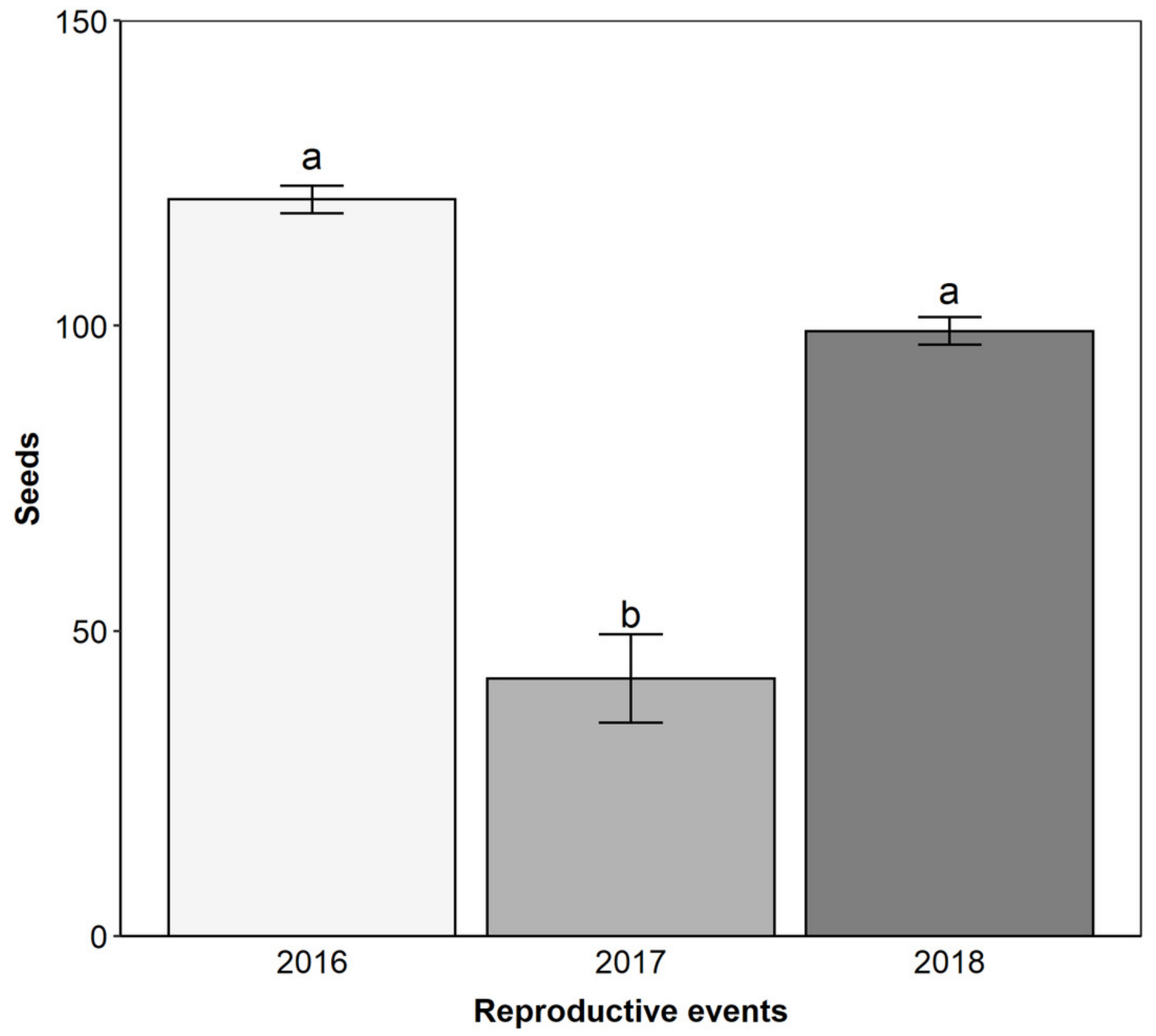




\section{Figure 5}

fig5A - Hummingbirds had higher efficacy than large bees in two reproductive events.

Pollinator efficacy in the reproductive events of 2017 (A) and 2018 (B). Seeds = proportion of fruits with seeds formed multiplied by the number of seeds in each fruit. Different letters show statistically significant difference $(p<0.05)$.
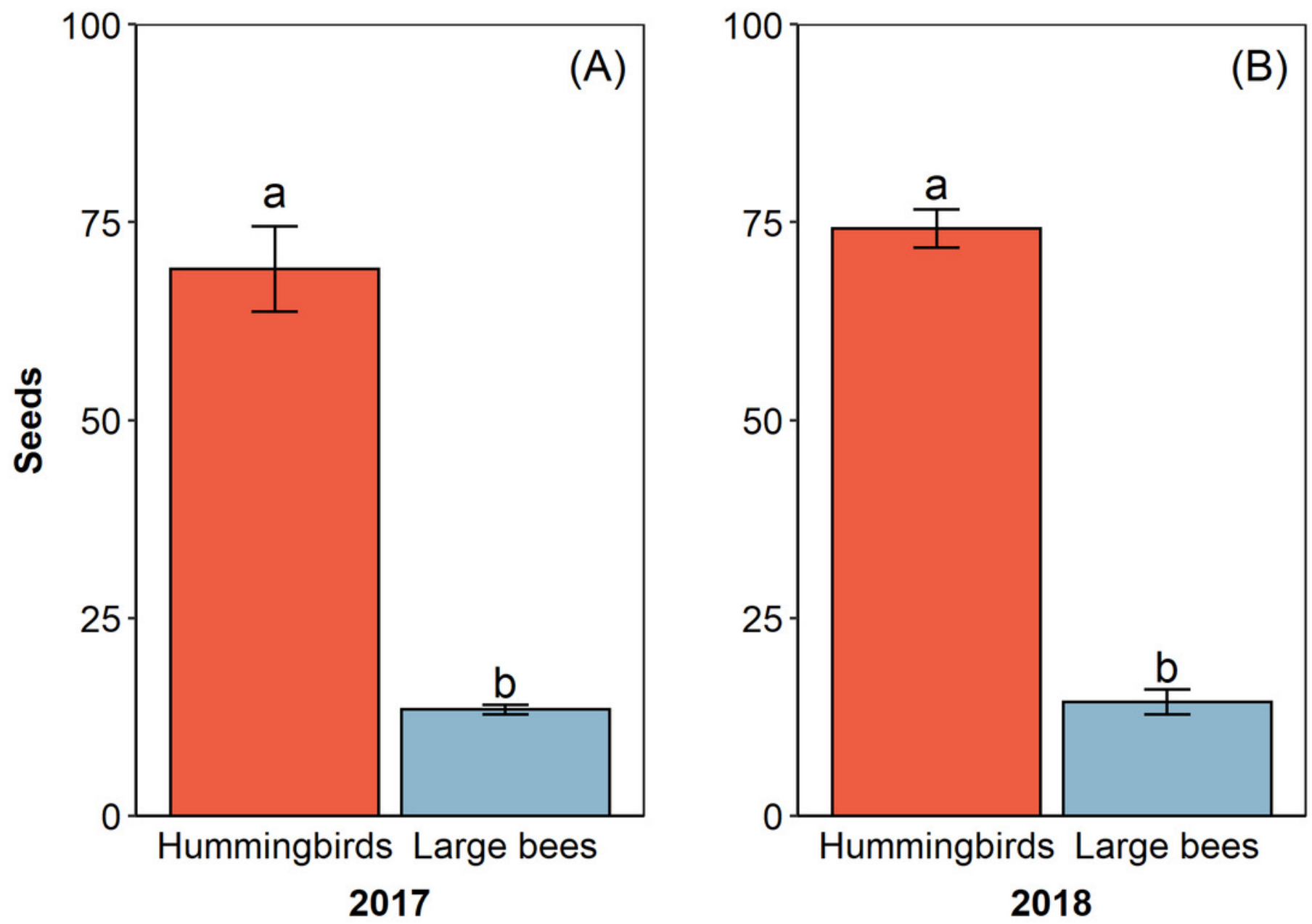


\section{Figure 6}

fig6 - Relative frequency of visits by each functional group in Edmundoa lindenii flowers varied among the four reproductive events.

The relative frequency of visits in the reproductive events of 2015, 2016, 2017 and 2018. HB = hummingbirds; $\mathrm{LB}=$ large bees; $\mathrm{SB}=$ small bees.

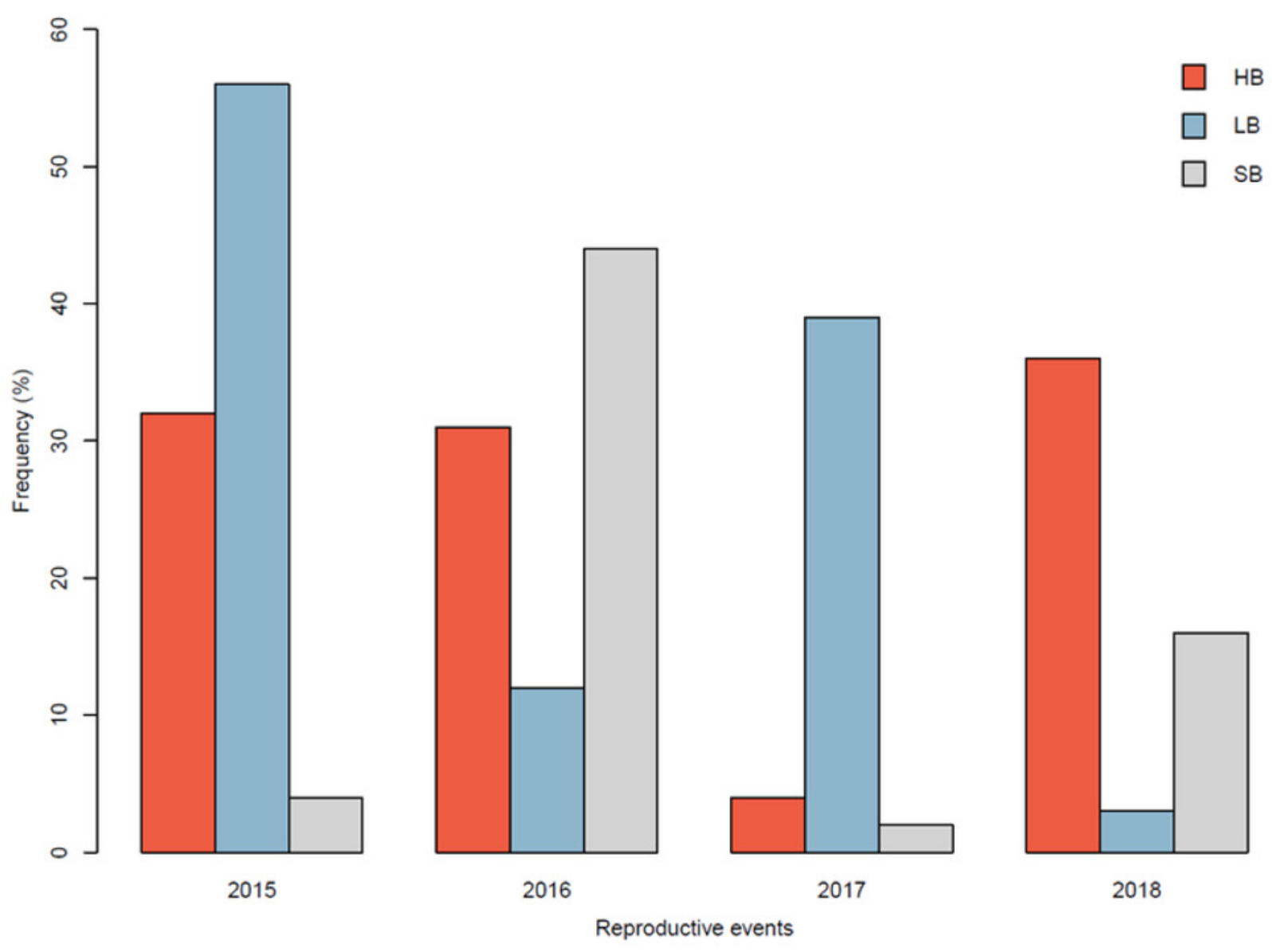




\section{Table $\mathbf{1}$ (on next page)}

The population of Edmundoa lindenii in PARNASO is self-incompatible and parthenocarpic.

Fruit and seeds production after hand pollination treatments at Serra do Órgãos National

Park, southeastern Brazil. Reproductive success = proportion of fruits with seeds multiplied by the number of seeds. 


\section{Table 1:}

2 The population of Edmundoa lindenii in PARNASO is self-incompatible and

3 parthenocarpic.

4 Fruit and seeds production after hand pollination treatments at Serra do Órgãos National Park,

5 southeastern Brazil. Reproductive success $=$ proportion of fruits with seeds multiplied by the

6 number of seeds.

\begin{tabular}{lccccc}
\hline Treatments & $\begin{array}{c}\text { Flowers } \\
\text { (n) }\end{array}$ & $\begin{array}{c}\text { Fruits with } \\
\text { seeds }(\mathbf{n})\end{array}$ & $\begin{array}{c}\text { Fruit } \\
\text { set }\end{array}$ & $\begin{array}{c}\text { Seeds } \\
\text { (mean } \pm \text { sd) }\end{array}$ & $\begin{array}{c}\text { Reproductive } \\
\text { success }\end{array}$ \\
\hline $\begin{array}{l}\text { Spontaneous self- } \\
\text { pollination }\end{array}$ & 20 & 1 & 0.05 & 26 & 1.30 \\
Manual self-pollination & 49 & 4 & 0.08 & $126.00 \pm 58.17$ & $10.08 \pm 4.65$ \\
\hline \hline Cross-pollination total & 130 & 127 & 0.98 & $116.11 \pm 58.97$ & $113.64 \pm 61.27$ \\
\hline Cross-pollination 2016 & 26 & 23 & 0.89 & $126.57 \pm 53.66$ & $99.65 \pm 57.91$ \\
Cross-pollination 2017 & 48 & 48 & 1.00 & $138.44 \pm 63.47$ & $138.44 \pm 63.47$ \\
Cross-pollination 2018 & 56 & 56 & 1.00 & $98.88 \pm 54.65$ & $98.88 \pm 54.65$ \\
\hline \hline Natural conditions total & 131 & 108 & 0.82 & $119.08 \pm 66.31$ & $101.98 \pm 58.43$ \\
\hline Natural conditions 2016 & 49 & 45 & 0.92 & $131.19 \pm 55.58$ & $120.69 \pm 51.13$ \\
Natural conditions 2017 & 20 & 11 & 0.55 & $76.73 \pm 73.66$ & $42.20 \pm 40.51$ \\
Natural conditions 2018 & 62 & 52 & 0.84 & $118.04 \pm 70.23$ & $99.15 \pm 58.99$ \\
\hline
\end{tabular}

7 


\section{Table 2 (on next page)}

Floral visitors and the resources they have taken in Edmundoa lindenii flowers.

All records were made in 2015 to 2018 at Serra do Órgãos National Park, southeastern Brazil. Functional groups: HB = hummingbirds, $L B=$ large bees, $S B=$ small bees. Type of resources: $\mathrm{P}=$ pollen, $\mathrm{N}=$ nectar. 


\section{Table 2:}

2 Floral visitors and the resources they have taken in Edmundoa lindenii flowers.

3 All records were made in 2015 to 2018 at Serra do Órgãos National Park, southeastern Brazil.

4 Functional groups: $\mathrm{HB}=$ hummingbirds, $\mathrm{LB}=$ large bees, $\mathrm{SB}=$ small bees. Type of resources: $\mathrm{P}$ 5 = pollen, $\mathrm{N}=$ nectar.

\begin{tabular}{|c|c|c|c|}
\hline Family & Species & Functional group & Resource \\
\hline \multirow[t]{7}{*}{ Trochilidae } & Amazilia lactea (Lesson, 1832) & HB & $\mathrm{N}$ \\
\hline & Amazilia versicolor (Vieillot, 1818) & HB & $\mathrm{N}$ \\
\hline & Leucocholoris albicollis (Viellot, 1818) & HB & $\mathrm{N}$ \\
\hline & Phaethornis eurynome (Lesson, 1832) & HB & $\mathrm{N}$ \\
\hline & Ramphodon naevius (Dumont, 1818) & HB & $\mathrm{N}$ \\
\hline & Thalurania glaucopis (Gmelin, 1788) & HB & $\mathrm{N}$ \\
\hline & Amazilia fimbriata (Gmelin, 1788) & HB & $\mathrm{N}$ \\
\hline \multirow[t]{4}{*}{ Apidae } & Bombus morio (Swederus, 1787) & LB & $\mathrm{N} / \mathrm{P}$ \\
\hline & Bombus brasiliensis (Lepeletier, 1835) & LB & $\mathrm{N} / \mathrm{P}$ \\
\hline & Euglossa sp. & LB & $\mathrm{N}$ \\
\hline & Trigona spinipes (Fabricius,1793) & SB & $\mathrm{P}$ \\
\hline
\end{tabular}

6 


\section{Table 3 (on next page)}

The pollination efficacy of hummingbirds was higher than efficacy of large bees in Edmundoa lindenii.

ANOVA results on the pollination efficacy of functional groups of pollinators of $E$. lindenii, measured by seed set after a single visit to the flower at Serra do Órgãos National Park, southeastern Brazil. 
1 Table 3:

2 The pollination efficacy of hummingbirds was higher than efficacy of large bees in

3 Edmundoa lindenii.

4 ANOVA results on the pollination efficacy of functional groups of pollinators of E. lindenii,

5 measured by seed set after a single visit to the flower at Serra do Órgãos National Park,

6 southeastern Brazil.

\begin{tabular}{lcccc}
\hline Effects & DF & F & p \\
\hline Reproductive event (year) & & & \\
\hline Functional group of pollinators & 1 & 71.07 & $<\mathbf{0 . 0 0 1}$ \\
Reproductive event : functional group & & & 0.860 \\
& 1 & 2.60 & 0.078 \\
\hline
\end{tabular}

7 


\section{Table 4 (on next page)}

The reproductive events and the functional groups of flower visitors of Edmundoa lindenii had an effect on the relative frequency of visits.

ANOVA results on the relative frequency of floral visits by functional groups during the reproductive events of 2015, 2016, 2017 and 2018 at Serra do Órgãos National Park, southeastern Brazil. 
1 Table 4:

2 The reproductive events and the functional groups of flower visitors of Edmundoa lindenii

3 had an effect on the relative frequency of visits.

4 ANOVA results on the relative frequency of floral visits by functional groups during the

5 reproductive events of 2015, 2016, 2017 and 2018 at Serra do Órgãos National Park,

6 southeastern Brazil.

\begin{tabular}{lccc}
\hline Effects & DF & Deviance & P (> Chi) \\
\hline Reproductive events (year) & 3 & 0.020 & 0.999 \\
Functional group of floral visitors & 2 & $\mathbf{2 6 . 3 9 2}$ & $<\mathbf{0 . 0 0 1}$ \\
Reproductive events : functional group & 6 & $\mathbf{2 4 4 . 5 6 2}$ & $<\mathbf{0 . 0 0 1}$ \\
\hline
\end{tabular}

7

8

9

10 